\title{
Lined storage facilities for mine waste - considerations and benefits
}

\author{
F.W. Gassner Golder Associates Pty Ltd, Australia \\ B.P. Wrench Golder Associates Pty Ltd, Australia
}

\begin{abstract}
The paper presents key design and operational considerations related to the intended performance of a facility. The paper provides a guide on what lining system concepts result in large, medium or small environmental benefits. The various components of a lining system and the associated design considerations and performance in a mining environment are described, both for base lining and capping systems for tailings and waste rock facilities.

The lining systems discussed include subgrade, single, composite and double lining system, as well as the drainage system and protection system over the top of the liner. The paper also considers the issue of durability of various liner materials in mine waste applications.
\end{abstract}

\section{Introduction}

Mining operations produce large quantities of residues from the extraction of ore from the earth. This residue may be in the form of tailings or waste rock. On many sites the waste rock and tailings are stored in facilities that are designed to minimise cost and are considered of lesser importance than other aspects of the mining operation. With the increased awareness of environmental issues and the associated liability, mining operations are considering options to address their liabilities with respect to these facilities. In addition increasingly stringent requirements from regulators and financial organisation mean that the operation must demonstrate that the environmental issues are addressed and managed in the short and long term.

Among other options the use of liner systems in the storage facilities is being considered to:

- control the rate of migration of liquids from the stored tailings, leach ore or waste rock

- limit the infiltration of rainfall into the stored tailings or waste rock

- limit the migration of oxygen into potentially acid generating waste rock and tailings.

Lining systems are also used to limit the loss of mineral rich 'pregnant' solutions from heap leach pads. These solutions may be acidic or alkaline (hence, generally present a risk to the environment) and contain concentrated solutions of the ore, which are directed to a processing plant for recovery. The pregnant solutions therefore present value to the owner and, in most instances, pose a risk to the environment.

In some tailings facilities, where specific geotechnical conditions warrant it, lining systems may also be used to increase the quantity of water returned to the plant from the tailings storage facility (TSF) by limiting the rate of seepage from the base of the TSF. This is however more the exception, as many tailings are of low permeability.

\section{$2 \quad$ Lining system options}

Facilities can be lined in two ways:

- Base and side liner systems which control lateral and downward migration of liquid residues (leachate).

- Cap system which reduces the inward infiltration of air and/or water into the facility. A cap system can be progressively constructed after a part of the facility has been filled to the design capacity to better manage the potential environmental risks.

The rest of this paper will concentrate on the liquid seepage aspect of liner systems only. 
A lining system generally comprises several components, a liner, and a pressure reduction system directly above the liner, with a liquid extraction system. The liner may have one or more elements depending on the design seepage rate through the liner system. Similarly the pressure reduction system may comprise one or more components depending on the maximum design pressure over the liner system. The liner and pressure reduction system together create a system with a maximum design seepage migration rate. The extraction system removes the collected liquids to sustain the liners pressure reduction.

Lining systems for mine waste storage facilities generally employ a combination of materials and components that complement each other to achieve the desired outcome. The following liners could be considered:

- Single liner, either from natural materials or geosynthetic materials. Single liners may comprise compacted soil layers with a specified maximum permeability (typically less than $1 \times 10^{-9} \mathrm{~m} / \mathrm{s}$, with some instances where $1 \times 10^{-8} \mathrm{~m} / \mathrm{s}$ is appropriate), or a geosynthetic clay liner (GCL), or a geomembrane liner (typically at least 750 micron thick).

- Composite liner, which is generally two types of liners that complement each other and are usually constructed by a combination of either natural materials with at least one geosynthetic liner, or alternatively both components, may be geosynthetic materials. These two components must be in intimate contact to complement each other and form a composite system.

- Dual liner system, which are two liners either single or composite, which are separated by a drainage system. The drainage system between the two liners provides a leak collection or secondary drainage system.

A large number of natural and geosynthetic materials are available for consideration for lining systems. The geosynthetic materials that are typically considered, based on price, performance, availability and performance history are:

- polyethylene, including high density and linear low density

- $\quad \mathrm{PVC}$

- elastomeric bituminous

- polypropylene

- GCL, which is a thin layer of refined bentonite encapsulated between layers of geosynthetics.

There are also some variations to the polyethylene liners and other proprietary materials that may be considered.

Figure 1 shows a composite liner of GCL and geomembrane being installed for a tailings storage facility.

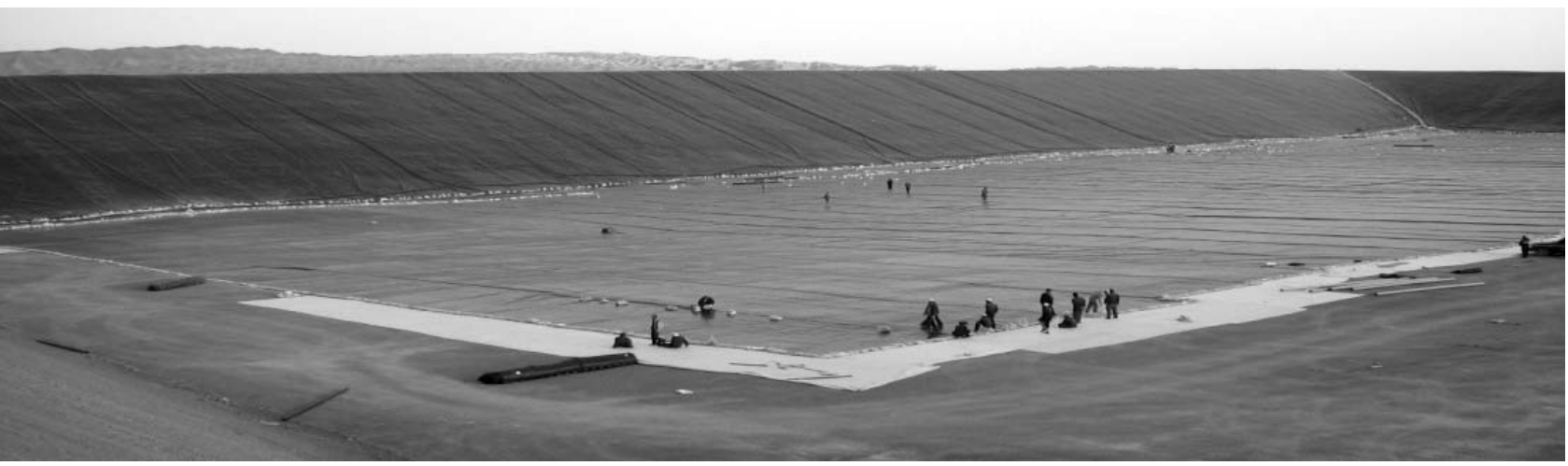

\section{Figure 1 Composite lining of a tailings storage facility}

The pressure reduction system that forms part of the liner system is a liquid collection layer that includes a series of perforated collection pipes or similar components spaced at intervals to suit the topographic shape 
of the layer and designed to limit the pressure in the collection layer. For the purpose of this paper the collection components will be called pipes.

The collection layer may be a granular fill layer or a geosynthetic layer that has a high porosity. The design of drainage layers is generally limited by the risk of damage during construction of the underlying liner system, the drainage layer materials and the collection pipes.

The pressure reduction systems may comprise a collection layer with a specified thickness of aggregate or sand (generally at least $250 \mathrm{~mm}$ thick) with an associated permeability (generally more than $1 \times 10^{-6} \mathrm{~m} / \mathrm{s}$ ) or a geocomposite drainage system. The geocomposite drainage system is usually at least $4 \mathrm{~mm}$ thick, and may be up to $100 \mathrm{~mm}$ thick, and comprises a high porosity core element with a geotextile cover to control the migration of fine materials into the core when seepage occurs. These layers are generally light weight and very flexible, but are susceptible to damage during construction. Most commercially available geocomposite systems have a very large flow capacity, but the capacity of most systems is reduced when a compressive load (from overlying materials) is applied which reduces the void space of the inner core.

A collection system using crushed rock aggregate constructed over a geosynthetic liner presents a risk of puncture or accelerated degradation of the geosynthetic liner. Where aggregate is used in contact with a geosynthetic liner the risk of damage may be reduced by the appropriate selection of the liner material, and the inclusion of a cushion layer between the aggregate and the liner. Cushion layers can be a geotextile layer of specific performance or a layer of small sized particles, such as sand, between the liner and larger particle aggregate layer. The smaller particles layer however will be of lower permeability which should be considered in the design of the pressurisation reduction system and seepage assessment of the liner system.

\section{Design and performance considerations}

\subsection{Liners}

\subsubsection{Natural materials}

Clayey soils have traditionally been used to construct liner systems below storage facilities. Occasionally naturally occurring clay will underlie the storage site and will form a seepage restriction zone but in most cases a liner will be constructed using materials from borrow sources near the site. Construction of engineered soil liners compromises preparation of the foundation, moisture conditioning of the liner materials, placement and compaction of the materials in layers generally between $150 \mathrm{~mm}$ to $300 \mathrm{~mm}$ in thickness, and maintaining the moisture content of the liner until it is covered.

It should be noted that the selected thickness of layers is not related to achieving compaction density, but is related to the requirement to knead to the clayey material to achieve a uniform structure and distribution of moisture in the clay.

The technology and experience required to construct clay liners is generally well developed in the engineering industry from decades of lining construction in dam and landfill projects. Issues such as material variability, drying and shrinkage cracking of compacted layers, construction access and possible increases in permeability due to geochemical reactions with the residue must be considered in the design.

Compacted clay liners are generally constructed to a minimum thickness of about $0.5 \mathrm{~m}$ and in at least three layers to limit the risk of layer discontinuities extending through the entire liner thickness (Heibrock and Demmert, 1992).

\subsubsection{Geosynthetic liners}

Most geosynthetic liners are thin and as such are susceptible to damage during storage, transport, installation and possibly during operation. The design of liner systems that include geosynthetic components therefore must consider these risks and engineering should include the creation of redundancies and measures to reduce and manage these risks. A well engineered system, once properly installed can significantly reduce the risk of migration of contamination from the facility into the environment.

The performance of the plastics type geomembrane liner systems is related to the following points: 
- For an intact geomembrane liner, the advective flow through a geomembrane liner is non-existent for practical considerations in mining projects. Chemical migration of some elements does occur through diffusion through the liner.

- All geomembrane liners leak due to defects in the installed system related to manufacture defects or defects during installation. These defects typically occur at joints in panels that make up the overall liner system, or that may develop at stress concentrations as the liner is loaded or from degradation of the liner.

- To limit the occurrence of defects in the installed liner an effective quality control and assurance programs must be implemented during construction. The effectiveness of a liner can be significantly reduced due to defects. Once a critical number of defects occur a geomembrane liner becomes ineffective.

For a GCL the performance of the liner is related to the permeability of the bentonite component of the liner, and the effectiveness of the joints between panels. The typical permeability of commercial GCL's is in the range between $1 \times 10^{-11} \mathrm{~m} / \mathrm{s}$ to $5 \times 10^{-10} \mathrm{~m} / \mathrm{s}$. Hence the flow rate through the GCL system is linearly related to the hydraulic head over the liner.

Both geosynthetic liner types described above could be affected by chemical and temperature effects on the liner materials. Whilst experience with installing geomembrane liners in mining projects extends over many years, results of durability assessments of various materials in specific mining waste conditions have mostly been published recently (Benson et al., 2008; Gassner and Scheirs, 2010; Hornsey et al., 2009; Rowe et al., 2008; Gulec et al., 2004). It should be noted that geosynthetic materials are not inert as may be assumed. In many mining environments the chemical conditions are significantly different to that in landfill conditions, where most of the liner durability testing and experience has been collected and published.

Most geomembrane types are also affected by temperature, with a general trend of higher temperatures resulting in a shorter design life. For example HDPE geomembrane that is widely used in the mining industry, the period between installation and where mechanical degradation starts to occur is halved for every $10^{\circ} \mathrm{C}$ increase in operational temperature, i.e. for a particular geomembrane the design life at $25^{\circ} \mathrm{C}$ may be 50 years, but at $35^{\circ} \mathrm{C}$ the design life will reduce to 25 years. This is generally not an issue for most TSF liners, but is an issue for acid rock drainage storage facilities and heap leach pads where the exothermic reaction of the oxidation process can result in high temperatures in the lining system.

GCL's in the as-manufactured state are basically dry and initially have the permeability of silt or sand, depending on the form of bentonite used in the manufacturing process of the GCL. When the GCL is in contact with water, the bentonite in the GCL structure hydrates and the bentonite swells becoming a gel with a low permeability.

The bentonite in the GCL may be affected by ion exchange with the soil or liquid in contact with the GCL. This effect generally reduces once the liner is confined under high pressure. Depending on the chemical composition of the contact material, ion exchange may increase the permeability of the bentonite by up to two orders of magnitude relative to the water permeability of the GCL, or have a lesser or negligible effect. The ion exchange process is generally a once off effect.

The permeability of specific GCL's has also been measured to reduce under specific chemical conditions due to chemical effects in the bentonite (Benson et al., 2008).

In the early stages of construction when the GCL may be exposed to the weather the bentonite in the GCL is subject to possible erosion from rainfall. This issue does not generally exist once the GCL is covered unless large seepage flows occur in a coarse drainage layer over the top of the GCL.

Many mine waste storages have a large thickness of stored tailings, ore or rock. As a result the liner system and the subgrade may be subject to very high compression loads. The durability and integrity of the liner system, particularly a thin geosynthetic liner, must be assessed in relation to the imposed load. Typical considerations include:

- the risk of puncture of the liner from hard particles in the subgrade or in the overlying pressure reduction system 
- settlement of the subgrade, and subsequent differential deformation of the liner system.

The high compression load on a compacted clay liner or GCL may also have a positive effect, in that it may result in a reduction of the permeability of the bentonite or compacted clay due to consolidation. This process may result in pore water pressure increases in the clay component of the liners as the load is applied.

\subsection{Pressure reduction system}

Pressure reduction systems constructed using natural materials are usually stable with respect to changes in material properties due to temperature or chemical effects. Where the pressure reduction system is manufactured from geosynthetic materials, typically polyethylene and similar materials, the system is subject to similar durability issues as the geomembrane materials described in the previous section.

The design of a geosynthetic pressure reduction system should carefully consider the effects of the high compression loads that will be applied by the overlying materials, and the stresses from construction activities. Most geosynthetic materials are of much lower stiffness than natural drainage materials, so elastic and creep deformation of the geosynthetics systems should be considered in the estimating the medium to long term flow capacity of the system. The effect of higher temperature on geosynthetic materials is generally to reduce the stiffness and increase the creep.

In many mining operations pressure reduction systems are subject to clogging as a result of chemical precipitates filling the void space in the pressure reduction system. This can lead to a significant reduction in permeability of the layer. There are options to partially control this mechanism and limit the risk of clogging. The design of the pressure reduction system needs to assess the geochemistry of the liquids and the risk of possible clogging.

The pressure reduction system should be designed to effectively drain the collected liquid in the collection layer, so that the pressure is limited to the design limits, thereby limiting seepage through the liner system. The collection system will collect some sediment from the overlying mine waste, as any filter system over the collection system will allow some fine material to pass through the filter as part of the filter design. Constructing the collection system with a suitable grade reduces the risk of sediment buildup in the collection system. Selection of the grade is usually dependent on the topography, redundancy of the system, and the design and properties of the mine waste.

All collection system should include a filter between the mine waste and the top of the high porosity layer of the drainage layer. The filter can be a geotextile or graded natural material to suit filter criteria. The filter should also consider the potential effects and risk of chemical clogging. It should be noted that if a continuous drainage layer is constructed over the liner, if the filter does clog it effectively creates another liner over the top of the drainage layer, which may further reduce the seepage rate through the liner system. Clogging of the filter may however increase the retention of water over the top of the clogged filter, which may affect the stability of external slopes of the mine waste rock or heap leach pad facilities.

\subsection{Indicative performance of overall lining systems}

Table 1 presents the range of seepage rates that may occur through a liner system under various conditions. These seepage rates are intended to provide an indication only, since local conditions and quality assurance will affect the permeability of the liner system as detailed in earlier sections of this paper.

The hydraulic heads selected for inclusion in the seepage rates are not intended to represent any limit or accepted values but are intended to demonstrate the effect of pressure head on the seepage rate.

For geomembrane liners the rate of seepage is related to the defects in the liner, and in particular wrinkles with defects. Wrinkles form a void space below the geomembrane which for stiff geomembrane stays a void even when high compression loads are applied over the top of the liner. This has been confirmed by testing and research by Brachman and Guidina (2008), among others, for HDPE geomembrane. A defective wrinkle allows seepage to migrate laterally in the void under the geomembrane, making the geomembrane less effective over that part of the composite liner system. 
Defects and wrinkles can be significantly reduced in the liner system through effective quality control and assurance during construction. Control of these issues has a direct beneficial effect on the performance of the liner system.

It should be noted that it is not practical to expect an impermeable liner in the field.

Table 1 Indicative seepage rates through liner systems

\begin{tabular}{lll}
\hline Liner System & $\begin{array}{l}\text { Hydraulic } \\
\text { Head }(\mathbf{m})\end{array}$ & $\begin{array}{l}\text { Seepage Rate } \\
(\mathbf{L} / \mathbf{h a} / \mathbf{d a y})\end{array}$ \\
\hline $\begin{array}{l}\text { Single compacted clay liner (CCL) } \\
(600 \mathrm{~mm} \text { thick, permeability } 1 \times 10-9 \mathrm{~m} / \mathrm{s})\end{array}$ & 0.3 & 430 \\
$\begin{array}{l}\text { Single geomembrane liner on sand subgrade } \\
\text { with assumed 10 No 5 mm diameter holes/ha }\end{array}$ & 0.3 & 4,300 \\
$\begin{array}{l}\text { Single geomembrane liner on clayey subgrade } \\
\text { (permeability 5 } \times 10-8 \mathrm{~m} / \mathrm{s}) \text { with 3 } \times 10 \mathrm{~m} \text { long }\end{array}$ & 0.3 & 20,000 to 14,000 \\
$\begin{array}{l}\text { defective wrinkles } \\
\text { Composite liner, } 600 \mathrm{~mm} \text { CCL with }\end{array}$ & 3 & 650 \\
$\begin{array}{l}\text { geomembrane with 3 } \times 10 \text { m long wrinkles } \\
\text { with holes }\end{array}$ & 0.3 & 3,450 \\
& 3 & 45 \\
$\begin{array}{l}\text { Composite liner, GCL with geomembrane with } \\
3 \times 10 \mathrm{~m} \text { long wrinkles with holes }\end{array}$ & 0.3 & 6 \\
& 3 & 60 \\
$\begin{array}{l}\text { Dual composite liner (seepage through bottom } \\
\text { component) }\end{array}$ & 3 & 280 \\
\hline
\end{tabular}

\section{Operational considerations}

Once the liner system has been installed and has been covered by the first layer of tailing, ore or mine waste the system is relatively robust if the facility is operated as intended. The key residual risks to a base and side liner, once covered are:

- Increase in hydraulic head on the liner system if liquid in the pressure reduction system is not removed. This may increase seepage rate through the liner system and may reduce the slope stability of heap leach and waste rock slopes when located on the liner system. Flushing of the pressure reduction system may be included in the maintenance program of the facility to remove built up sediment in collection pipes, to further control the risk of increased hydraulic head in the system.

- Slope movements on the liner system are generally very serious and put the liner integrity at significant risk. Hence the stability of any slope must be carefully monitored as specified in an operation and maintenance program. Such monitoring should also typically include measurement of hydraulic pressure on the liner. It should be noted that the interface of many lining systems poses a low friction interface which should be carefully assessed during the design of the facility to control stability of slopes.

- Mine tailings placed into storages generally experience considerable consolidation settlement. Settlement next to side liner results in relative movement between the liner and the tailings. To limit the risk of drag strains being imposed on the side liner the design of the liner system may include a slip sheet over the top of the liner system. 
- Some cap systems may require maintenance while vegetation is established on the surface soils. Typically this involves replacing any cover material that may have eroded and re-seeding. A cap system should include cover material over the liner system to provide protection from puncture and limit degradation, and in the case of GCL to provide confinement and source of moisture to limit the propensity of drying out of the bentonite. To achieve a long term stable cover a cap is generally designed with gentle grades which suits most liner types with respect slope stability.

\section{Conclusion}

In summary, mine facilities are large structures that owners recognise potentially pose a risk to the environment. This paper provides an indication of the risk reduction options that exist to designers to limit the risk of outward migration of seepage from mine waste facilities or inward migration of air into mine wastes that may oxidise. The paper also presents some of the conditions and considerations that may impact on the performance of the risk reduction system.

\section{References}

Benson, C.H., Wang, X., Gassner, F.W. and Foo, D. (2008) Hydraulic Conductivity of Two Geosynthetic Clay Liners Permeated with an Aluminium Residue Leachate', GeoAmericas 2008, Cancun, Mexico.

Brachman, R.W.L and Guidina, S. (2008) Geomembrane strains from coarse gravel and wrinkles in a GM/GCL composite liner, Geotextiles and Geomembranes, Vol. 26, No. 6.

Gassner, F.W. and Scheirs, J. (2010) Durability of geosynthetic liners in high pH environments, 9th International Conference on Geosynthetics, Brazil.

Gulec, S.B., Edil, T.B. and Benson, C.H. (2004) Effect of acidic mine drainage on the polymer properties of an HDPE geomembrane, Geosynthetics International, Vol. 11, No. 2.

Heibrock, G. and Demmert, S. (1992) Auswirkung von Schwankungen der Durchlässigkeit von Mineralischen Abdichtungen, Institut für Grundbau der Ruhr-Universität Bochum, Heft 20.

Hornsey, W.P., Scheirs, J., Gates, W.P. and Bouazza, A. (2009) The Impact of Mining Solutions/Liquor on Geosynthetics, Geotextile and Geomembranes, Vol. 16, No. 1-8.

Rowe, R.K., Islam, M.Z. and Hsuan, Y.G. (2008) Leachate chemical composition effects on OIT depletion in an HDPE geomembrane, Geosynthetics International, Vol. 15, No. 2. 
